\title{
SOBRE LOS INICIOS DEL ESPIRITISMO EN ESPAÑA: LA EPIDEMIA PSÍQUICA DE LAS MESAS GIRATORIAS DE 1853 EN LA PRENSA MÉDICA ${ }^{1}$
}

\author{
Ángel González de Pablo
}

Unversidad Complutense. Madrid

\section{RESUMEN}

Este trabajo estudia, a través de la prensa médica española, el episodio de las mesas giratorias y parlantes que tuvo lugar entre abril y julio de 1853. Se analizan sucesivamente su recepción por los médicos, las experimentaciones que llevaron a cabo y las explicaciones que le dieron. Asimismo, se consideran las repercusiones que originó esta epidemia psíquica: la atracción de la atención hacia la actividad mental inconsciente, el fomento que supuso para el magnetismo animal y el impulso que dio a la aparición del espiritismo.

PALABRAS CLAVE: Mesas giratorias, mesas parlantes, espiritismo, ocultismo, magnetismo animal, prensa médica

\begin{abstract}
This paper studies the table-turning and table-tapping episode that took place between April and July of 1853 through the Spanish medical press. It is successively analyzed its reception by the doctors, the experiments they carried out and the explanations they gave to that event. Besides, it is considered the repercussions originated by this psychological epidemic: the focusing of the attention towards the unconscious mental activity, the support that it was to the animal magnetism and the impulse that it gave to the appearance of the spiritualism.
\end{abstract}

KEY WORDS: Table-turning, table-tapping, spiritualism, occultism, animal magnetism, medical press

1 Este trabajo se ha realizado dentro del proyecto de investigación HUM20040077/HIST financiado por el Ministerio de Educación y Ciencia. 


\section{LA APARICIÓN Y PROPAGACIÓN DEL ESPIRITISMO}

El espiritismo moderno comenzó, según viene siendo admitido ${ }^{2}$, a finales de la década de 1840 en los Estados Unidos. Como señaló Ellenberger, ambas circunstancias, la temporal y la espacial, no fueron casuales. Las sectas religiosas y los movimientos espirituales eran allí numerosos y dinámicos, lo que hacía que aparecieran continuamente nuevas congregaciones, sectas o hermandades y que pastores y fieles cambiaran a menudo de creencias. Además, los nuevos descubrimientos - como fue el caso del telégrafo, presentado en 1833 por Samuel Morse (1791-1872) — excitaban la imaginación de la gente, ocasionando que toda novedad, por fantástica que fuera, pudiera ser considerada como posible y digna de ser examinada. Así las cosas, "un incidente aparentemente trivial se convirtió en el punto de partida de un epidemia psicológica de inesperada amplitud: la aparición y divulgación del espiritismo»»3.

2 Acerca de la historia del espiritismo existe una cuantiosa bibliografía. Algunas de las obras principales son: GIBIER, P. (1922), El espiritismo (faquirismo occidental): Historia, doctrina y hechos [ed. orig. fr. 1886], trad. esp. de E. Shaíah, Madrid, Biblioteca del Más Allá, Imprenta de «El Adelantado de Segovia»; PODMORE, F. (1902), Modern Spiritulism: A History and a criticism, London, Methuen; HILl, J. A. (1911), Spiritualism: Its History, Phenomena and Doctrine, London, Casell \& Co.; Doyle, A. C. (1983), Historia del espiritismo: Sus hechos y sus doctrinas [ed. orig. ing. 1926], trad. esp. de E. D. Retg, Madrid, Eyras; GAULD, A. (1968), The Founders of Psychical Research, London, Routledge \& Kegan Paul; Brown, S. (1972), The Heyday of Spiritualism, New York, Pocket Books; Moore, R. L. (1977), In Search of White Crows: Spiritualism, Parapsychology, and American Culture, New York, Oxford University Press; BRANDON, R. (1983), The Spiritualists: The Passion for the Occult in the Nineteenth and Twentieth Centuries, London, Weidenfeld \& Nicolson; GAULD, A. (1983), Mediumship and Survival: A Century of Investigations, London, Paladin; OpPENHEIM, J. (1985), The Other World: Spiritualism and Psychical Research in England, 1850-1914, Cambridge, Cambridge University Press; Beloff, J. (1993), Parapsychology: A Concise History, New York, St. Martin's Press; Crabtree, A. (1993), From Mesmer to Freud: Magnetic Sleep and the Roots of Psychological Healing, New Haven \& London, Yale University Press; BLACKMORE, S. (1994), «Parapsychology», en: Colman, A. M. (ed.), Companion Encyclopedia of Psychology, 2 vols., London \& New York, Routledge, II, 971-989; LuCKHURST, R. (2002), The Invention of Telepathy, 1870-1901, Oxford, Oxford University Press; y Cox, R. A. (2003), Body and Soul: A Sympathetic History of American Spiritualism, Charlottesville \& London, University of Virginia Press.

También se cuenta con excelentes repertorios bibliográficos sobre espiritismo. Imprescindibles son: CAILlET, A. L. (1912), Manuel bibliographiques des sciences psychiques ou occultes, 3 vols., Paris, L. Dorbon; y Crabtree, A. (1988), Animal Magnetism, Early Hypnotism, and Psychical Research, 1766-1925. An Annotated Bibliography, White Plains, New York, Kraus International.

3 Ellenberger, H. (1976), El descubrimiento del inconsciente. Historia y evolución de la psiquiatría dinámica [ed. orig, ing. 1970], trad. esp. de P. López Onega, Madrid, Gredos, p. 111. 
En diciembre de 1847, John Fox, un herrero metodista, se trasladó a Hydesville, un pequeño villorrio cerca de Rochester, en Nueva York ${ }^{4}$. En marzo del año siguiente la vida familiar se vio alterada por unos extraños sucesos —unos ruidos que parecían provenir de las paredes - que tenían a las dos hijas del matrimonio Fox como protagonistas: Margaret de 15 años y Kate de 12. A finales de mes los ruidos eran ya tan habituales que las niñas comenzaron a jugar con ellos: chasquearon los dedos y dieron palmadas y dijeron a los sonidos que respondieran, lo que estos hicieron de buena gana casi inmediatamente. La señora Fox pidió entonces que sonaran diez golpes y cuando su solicitud fue concedida requirió que los golpes señalaran la edad de sus hijas, lo que también fue contestado con exactitud. Acto seguido preguntó si era un hombre y nada sucedió, pero cuando inquirió si era un espíritu el silencio dejó paso a rápidos y sonoros golpes. Pronto acudieron los vecinos y se estableció un sencillo código que permitía respuestas de sí o no a las preguntas. Se supo así que el espíritu golpeador era el de un buhonero muerto a los treinta años y enterrado en el sótano.

Ante estas revelaciones, los Fox fueron obligados por el dueño de la vivienda a abandonarla. La familia se trasladó a la casa de David, el hijo mayor, y los golpes continuaron también allí, siempre en presencia de las dos hijas. Se decidió entonces separarlas y Kate fue enviada a vivir con otra hermana, Leah, en Rochester, pero los golpes siguieron sintiéndose tanto en la casa de David como en la de Leah. Fue entonces cuando los fenómenos en torno a Kate aumentaron de rango. Empezaron a verse objetos volar por los aires, las camas eran sacudidas por la noche, los objetos cambiaban de sitio, los instrumentos musicales tocaban solos y las mesas y las sillas daban golpes con las patas, se volcaban o se movían.

En Rochester, Kate trabó relación con Isaac y Amy Post, un matrimonio cuáquero conocido de los Fox. La señora Fox había empelado el alfabeto para obtener el nombre del espíritu de Hydesville - Charles Rayn-, pero esa práctica no tuvo continuidad. Y fue realmente Isaac Post el que desarrolló un método de deletrear mensajes de los espíritus consistente en recitar sucesivamente la serie de las letras del alfabeto y seleccionar las letras señaladas por un golpe (por ejemplo, para la palabra «Charles» el espíritu golpeaba sucesivamente, en el primer desfile del alfabeto, las letras $\mathrm{C} \mathrm{y} \mathrm{H}$; en el segundo, la

4 Resalto, en esta rememoración de la historia, casi legendaria, del comienzo del espiritismo en 1848, a la que prácticamente todas las historias del espiritismo hacen referencia con algunas variantes, los aspectos que permiten comprender algunos puntos básicos del fenómeno de las mesas giratorias. 
A y la R; en el tercero, la L; y en el cuarto, la E y la S). Esta forma de comunicarse acabó recibiendo el nombre de «telegrafía espiritual» por su parecido con el reciente descubrimiento de Morse. El primer mensaje que se telegrafió espiritualmente en la casa de los Post fue «We are all your dear friends and relatives».

Con el traslado de la casa Fox a la casa Post se operó un giro radical en los comienzos del espiritismo que determinó su desarrollo posterior. En primer lugar, se vio que no sólo había un espíritu (con los Fox el único que se manifestó fue el de Rayn) sino varios; y además quedó abierta la posibilidad de comunicarse con familiares y seres queridos muertos, lo que inflamó enormemente la imaginación y la curiosidad de la gente y constituyó un factor esencial para la fulgurante extensión del espiritismo. En segundo lugar, las manifestaciones físicas aleatorias se convirtieron, con el uso de la telegrafía espiritual, en mensajes inteligibles. Y, en tercer lugar, las mesas se convirtieron en el principal locus de la comunicación espiritual, ya que a partir de entonces los golpes, que habían surgido previamente en paredes, suelos y mobiliario diverso, pasaron a localizarse preferentemente en las mesas de la sala de estar o del comedor de las casas.

En una atmósfera propicia por la importante presencia del mesmerismo, de la frenología, del misticismo y de las utopías sociales y por la ausencia de una ortodoxia religiosa, las noticias de los «Rochester rappings» se difundieron velozmente y en muy pocos años el espiritismo se propagó por los Estados Unidos $^{5}$. Con su expansión, las hermanas Fox, convertidas en celebridades ${ }^{6}$, fueron reemplazadas por otros médiums más completos. Estos especialistas desarrollaron nuevas formas de comunicación con los muertos, entre ellos la escritura automática y el uso de sus propias voces.

Pero, con todo, el rasgo más característico de esta primera etapa del espiri-

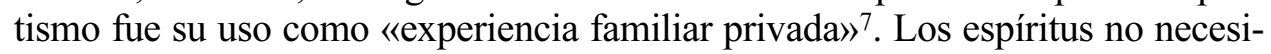
taron en la mayor parte de los casos de médiums profesionales ni de escenarios especiales para trabar contacto con los vivos. Podían hacerlo en los hogares co-

5 OPPENHEIM (1985), p. 11

6 La fama de las hermanas Fox fue enorme, aun a pesar de que desde el principio hubo una considerable controversia en torno a ellas. Algunos investigadores afirmaron que los ruidos los producían las propias jóvenes haciendo crujir sus articulaciones. En una dramática palinodia en 1888 las Fox así lo reconocieron. Los detractores del espiritismo tomaron esta confesión como el punto final de la cuestión, pero sus seguidores argumentaron que las hermanas se habían convertido entonces en alcohólicas, se encontraban en la miseria y fueron sobornadas para confesar el fraude. BLACKMORE (1994), p. 972.

7 CRABTREE (1993), p. 234. 
munes y corrientes y a través de personas del círculo familiar. El espiritismo fue así en sus comienzos un movimiento muy popular, lo cual determinó sus múltiples ramificaciones posteriores.

\section{LAS MESAS GIRATORIAS INVADEN EUROPA}

Un fenómeno tan sorprendente como el del espiritismo apenas tardó cinco años en sobrepasar las fronteras estadounidenses y llegar a Europa. Y la forma de hacerlo fue a través de una manifestación física muy concreta: las mesas giratorias ${ }^{8}$. El Boletín de Medicina, Cirugía y Farmacia dio la siguiente descripción inicial de éste fenómeno:

«Trátase de hacer girar y moverse en diversos sentidos una mesa, un sombrero o cualquier otro objeto de gran peso, sin más que colocarse alrededor de él tres o más personas, apoyando ligeramente en su superficie las manos, extendidas y distantes entre sí una o más pulgadas, teniendo cuidado de no tocarse mutuamente por ninguna parte del cuerpo sino por los dedos pequeños de las manos que deben cruzarse uniformemente el de la derecha de uno sobre el de la izquierda del inmediato o viceversa. Así queda formada la cadena magnética en virtud de la cual, al cabo de cierto tiempo, que varía desde algunos minutos hasta una hora u hora y media, el objeto que sirve para el experimento empieza a oscilar primeramente y a girar después con una velocidad que se aumenta por instantes, arrastrando en su movimiento a las personas que forman la cadena $\iota^{9}$.

Todo comenzó a principios de abril de 1853 cuando los periódicos alemanes dieron cuenta de una serie de extraños acontecimientos que guardaban relación con veladores y mesas de cuarto de estar. Según estos artículos, el desencadenante había sido el envío por parte de un comerciante de Nueva York a su hermano residente en Bremen de unas instrucciones para reproducir las manifestaciones físicas que eran ya tan comunes en América. El hermano las puso a su vez en conocimiento de un tal Dr. Andrée y ambos determinaron poner en práctica el experimento,

«consiguiendo a las primeras tentativas hacer girar una mesa de caoba del peso de sesenta libras por medio de una cadena formada por ocho personas, de las cua-

8 El trabajo más extenso sobre el fenómeno de las mesas giratorias, especialmente en lo referente a las especulaciones sobre sus causas, es el capítulo de CRABTREE (1993) titulado «Table turning: speculations about unconsciuos mental activity», pp. 236-265.

9 Delgrás, M. (1853), «Nuevo descubrimiento magnético», Boletín de Medicina, Cirugía y Farmacia, 15 de mayo de 1853, 157-158; p. 157. 
les tres eran hombres y cinco mujeres de la edad de 16 a 40 años. El movimiento de rotación de la mesa llegó a hacerse tan rápido que apenas podían seguirle las personas que formaban la cadena, hasta que tocándose entre sí con los brazos o con la ropa la mesa quedó inmóvil, no sin volver a tomar su primitivo movimiento tan luego como volvieron a aislarse entre sí los primitivos operadores» ${ }^{10}$.

Este acontecimiento se reflejó en la Augsburg Gazette del 18 de abril de $1853^{11}$, fue reproducido casi inmediatamente en otros periódicos alemanes y franceses y, a partir de ahí, la moda de las mesas giratorias se extendió por Europa occidental con una rapidez sorprendente ${ }^{12}$. No hubo apenas en estos días otro tema de conversación en todo el continente. Tanto en los salones de la aristocracia y de las clases acomodadas como en los hogares más humildes la gente formó corros, cruzó sus meñiques entre sí y se dispuso alegremente a mover mesas. Un poco más tarde, además, las mesas no sólo giraron sino que crujieron, bailaron, levitaron y también empezaron a mandar mensajes por medio de golpes ${ }^{13}$.

La forma más común de transmitir mensajes consistía en el golpeo de una de las patas de la mesa sobre el suelo. Por lo demás, el mensaje podía descifrarse de variadas formas ${ }^{14}$ : bien la mesa daba golpes como si recorriera el alfabeto hasta pararse en la letra elegida o bien era uno de los participantes el que recitaba el alfabeto y la mesa se levantaba y golpeaba con una pata al sonar la letra adecuada (el método de Post). Fue mediante la búsqueda para

10 Ídem.

11 GuriÉRrez de LA VeGA, J. (1853a), «Las ciencias a tiro de beso: de cómo el magnetismo, la electricidad y otras cosas como estas han venido a sustituir a los juegos de prendas en sociedad, y del furor que tal entretenimiento está haciendo en los círculos de esta coronada villa», El Heraldo Médico, 19 de mayo de 1853, 113-115; p. 113; y ANÓNIMO (1853), «Magnetismo: Nuevo descubrimiento magnético», La Unión Médica, 22 de mayo de 1853, 117-119; p. 117.

12 Durante 1853 y 1854 las publicaciones sobre las mesas giratorias fueron cuantiosas. Véase: CRABTREE (1993), p. 237; y también en CRABTREE (1988) las numerosas referencias bajo las entradas de «table-knocking», «table-talking», «table-tapping» y «table-turning».

13 No es extraño así que el fenómeno recibiera así multitud de nombres: «mesas giratorias, «mesas movientes», «mesas danzantes, «baile de las mesas», «mesas golpeadoras», «mesas parlantes» y «repique de los espíritus». Lo mismo sucedió en todos los países europeos. En inglés se denominaron: «table moving», «table turning, «table rapping», «table tapping», «table tipping», «rotating tables», «responding tables» y «talking tables». «En francés: «tables tournantes», «tables parlantes», «tables répondantes» y «la danse des tables». En alemán: «Tischrücken», «Tischklopfen», «Tischsprechen», «Tischdrehen», «selbsbewegunde Tische», «tanzende Tische» y «somnanbule Tische». Cf.: CRABTREE (1993), p. 237.

14 CRABTREe (1993), pp. 238-239. 
hacer la comunicación con los espíritus más sencilla y rápida como se llegó a inventar lo que se llamo primero «psicógrafo» y "planchette» y más adelante «ouija». El primero en patentar uno de estos psicógrafos, consistente en un alfabeto pintado en un tablero sobre el que se hacía mover un puntero hasta que se oía el golpe de la pata al señalar una determinada letra, fue Adolphus Theodore Wagner, en Londres, en enero de 1854. Posteriormente los tableros parlantes se independizarían de la mesa, siendo el propio puntero, sobre el que se colaban los dedos de los participantes, el que se dirigía a las letras determinadas. Pero se siguió pensando que el movimiento del puntero se producía por las mismas fuerzas que hacían moverse a la mesa ${ }^{15}$.

\section{LAS MESAS GIRATORIAS LLEGAN A ESPAÑA}

Las primeras nuevas sobre las mesas giratorias llegaron a España en los días finales de abril y primeros de mayo; y con ellas, claro es, también se realizaron los primeros ensayos. Pero estos se multiplicaron repentinamente a raíz del artículo aparecido en La España en su edición del 10 de mayo ${ }^{16}$. Tal y como había pasado días antes en Alemania y Francia, la imaginación de las gentes se inflamó en masa a partir de entonces y los experimentos giratorios comenzaron a hacerse por doquier. No es por ello extraño que las primeras menciones del fenómeno aparecieran ya en la prensa médica española a partir del 15 de mayo.

En un primer momento, las noticias de los periódicos médicos se limitaron, con un cierto atropello, a reflejar los artículos aparecidos en la prensa política y de opinión, tanto extranjera como nacional. En relación con la foránea, de la cual la francesa fue con mucho la mayoritaria, remarcaron tres aspectos: 1) el carácter febril con que la población había acogido las experiencias magnético-giratorias con las mesas y otros útiles, así como lo exitoso de las mismas $^{17}$; 2) las sorprendentes facultades de las mesas, más allá de los

15 La ouija se patentó en Estados Unidos en 1890 como un juego de mesa, figurando Elijah J. Bond como inventor y William H. A. Maupin y Charles W. Kennard como titulares. Kennard creó una empresa ese mismo año y comenzó a vender ouijas con gran éxito comercial, éxito al que es posible que contribuyera su invención de que el nombre de ouija procedía de una palabra egipcia que significaba «buena suerte».

16 DELGRÁs (1953), p.157.

17 «La pasión, el delirio de los parisienses por los sombreros y las mesas giratorias bajo el impulso magnético son cada vez mayores. No es lícito dudar de la existencia del pasmoso fenómeno, pues las pruebas de buen éxito son demasiado numerosas para poderlo hacer». GUTIÉRREZ DE LA VEGA (1953a), p. 113. 
simples giros, que abarcaban desde sus aptitudes para el baile ${ }^{18}$ hasta sus capacidades adivinatorias, primero con cosas sencillas ${ }^{19}$ y luego con objetivos más complejos, en donde se empleaba ya el método alfabético de $\operatorname{Post}^{20}$; y 3 ) algunos episodios maravillosos que parecían superar toda capacidad de credibilidad, como fue el aparecido en el Durquerqueoise ${ }^{21}$.

De la prensa española se hizo hincapié, a su vez, en tres puntos: 1) La rapidez en la propagación de los experimentos y en la amplia extensión social de los mismos, que abarcó desde los hogares, los cafés, las tertulias, los ateneos o los casinos hasta la mismísima Casa Real. Isabel II y la familia real no pudieron resistirse, una vez que hubieron llegado a su residencia de Aranjuez las sorprendentes novedades, a ponerlas también en práctica de primera mano:

«Habiéndose hecho con tanta felicidad, en la noche del 8 [de mayo], por una familia residente hoy en Aranjuez, los experimentos magnéticos (...) S. M. la reina Isabel, que supo a los pocos momentos su buen éxito, quiso presenciar su repetición al día siguiente 9. En ese día por la mañana ya las mismas personas del 8 habían descubierto la aplicación feliz a otros muchos objetos además de las mesas y principalmente al cuerpo humano. Para presenciar todo esto, S. M. la reina Isabel, S. M. el Rey y S. A. R. la Serenísima Sra. Princesa de Asturias, con sus respectivas servidumbres, fueron a las 5 de la tarde a la casa de recreo, llamada del Labrador, adonde concurrió también, por invitación de su augusta hija, S. M. la Reina Madre, acompañada de sus dos hijas mayores y del Dr. Rubio. Por altos miramientos y precaución prudentísima no tomaron parte alguna, ni la más mínima, en estos experimentos, ni S. M. la reina Isabel, ni el ama de cría de la augusta Princesa. Todo se hizo por los demás circunstantes, teniendo S. M. la dignación de

18 «Una de las personas presentes se sentó al piano y ejecutó una polca o un wals: se dijo a la mesa que bailara y el mueble se puso a oscilar sin que los pies dejaran de tocar el suelo, por efecto de una ligera falta de equilibrio, pero con perfecto compás. Sus movimientos eran más pausados o más acelerados según la viveza del aire o de la pieza que se tocaba». Ídem.

19 «Se mandó a la mesa que indicara la edad de dos jóvenes que se encontraban en el número de los operadores (...); el mueble contestó levantando los pies del lado de la persona indicada y dando un número de golpes igual al de los años (...); se le ordenó indicara el nombre de una persona golpeando cuando lo oyera y, habiéndose pronunciado muchos, la mesa permaneció quieta hasta que oyó el verdadero». Ídem.

20 Ibídem, p. 115.

21 «Un buque tenía que virar de bordo en nuestro puerto, es decir, que hacer una evolución sobre sí mismo. En vez de emplear los métodos ordinarios, la tripulación se contentó con colocarse en círculo y aplicó sus manos sobre el puente, teniendo cuidado de formar la cadena magnética por la superposición del dedo pequeño y del pulgar; después de algunos minutos de espera se vio al buque obrar como por encanto la media vuelta deseada». Ibídem, p. 113. 
llamar a su presencia a los caballerizos de campo y oficiales de las escoltas para que viesen lo que nunca habían visto o experimentasen en sí mismos los efectos de la cadena magnética que sobre ellos hacían sus compañeros. La marcha de progresión en ambos rumbos, como el girar de las mesas, como la aplicación de la cadena al cuerpo humano y, en suma, cuantas tentativas se hicieron tuvieron el éxito más completo. SS. MM. se retiraron a su real palacio agradablemente sorprendidos ya bien entrada la noche $»^{22}$.

2) Los relatos de experimentos llevados a cabo por personas prestigiosas. Uno de los más detallados y precisos de esta primera hornada, en el que se hacen girar primero mesas y sombreros y luego personas, es el siguiente, al que, dada su considerable extensión, se cita a continuación de forma resumida:

«La primera experiencia (...) se verificó por la tarde. Cinco personas (...) formaron la cadena eléctrica. Alrededor de un velador de caoba muy pesado y con muchos adornos. Durante media hora no hubo novedad; pero, habiéndose cansado uno de los operadores (...), ocupó su puesto otro caballero muy nervioso, y cinco minutos después de este cambio la mesa empezó a oscilar, y en seguida a girar con tanta velocidad, que tiró a una de las señoras que formaban la cadena. Obtenido el movimiento, se reprodujo siempre que se quiso casi instantáneamente después de cada interrupción. En esta experiencia se observó repetidas veces el fenómeno del cambio de dirección siempre que se cambiaba la postura de los dedos pequeños (...)

«Por la noche se repitieron los experimentos. Empezóse con un sombrero colocado sobre una silla (...) Pasó una meda hora sin resultado alguno (...) Pensándose que ya no giraría el sombrero, se hizo la prueba de trasladarlo a un velador de mármol y, apenas estuvo tres minutos en él, cuando empezó a oscilar, a levantarse por un lado a veces hasta una pulgada, acabando por emprender la marcha rápidamente hacia el mediodía. Cuantas veces se repitió el ensayo se vieron los mismos resultados (...)

«Por último se aplicó la cadena, no ya a un mueble, sino a uno de los circunstantes, que es uno de nuestros más afamados artistas (...) La cadena se formó a la altura del pecho por cuatro personas, dos de cada sexo, y colocando los izquierdos sobre los derechos [los meñiques]. El operado cerró los ojos. A los cinco minutos empezaron a ser muy perceptibles las oscilaciones y poco después se pronunció el movimiento giratorio de derecha a izquierda. Cambiados los dedos se detuvo el movimiento, hubo fuertes y prolongadas oscilaciones y después comenzó a girar de derecha a izquierda. El experimento duró unos quince minutos $\mathrm{y}$, poco antes de concluir, los que formaban la cadena sentían perfectamente la vibración de los nervios paciente. Éste, teniendo los ojos cerrados, no sentía el movimiento giratorio y la sensación que experimentaba era la de figurarse más ligero que una pluma, casi como si estuviese suspendido en el aire» ${ }^{23}$.

22 Ibídem, p. 115.

23 Ibídem, pp. 114-115. 
Y 3) las primeras conclusiones a que se llegó en una primera reflexión sobre esta primera avalancha de experimentos. Entre ellas estaban: que la cadena magnética no sólo era aplicable a las mesas, sino también prácticamente a cualquier cosa, incluidas cajas, sombreros, fuentes y platos, jofainas con o sin agua, quinqués con aceite y encendidos o libros encuadernados en papel, tela o pasta, entre otros muchos objetos; que la cadena aplicada al ser humano producía el mismo movimiento giratorio que sobre las mesas; que las cadenas formadas con el meñique derecho sobre el izquierdo del vecino (las llamadas cadenas magnéticas de primera especie) producían movimientos circulares de izquierda a derecha y que las formadas con el meñique izquierdo sobre el derecho del otro (o cadenas magnéticas de segunda especie) ocasionaban giros de derecha a izquierda; que las cadenas parecían tener más fuerza cuanto mayor era el número de las personas que la formaban; que la edad juvenil de los partícipes en las cadenas parecía favorecer la producción de los fenómenos; que los sujetos sanguíneos y los nerviosos parecían ser los constitucionalmente más aptos para las cadenas; y que los que practicaban este ejercicio por primera vez eran poco aptos para la producción de los fenómenos y que los ya ejercitados lo estaban mucho más ${ }^{24}$.

Pasados los primeros momentos de escepticismo o hilaridad, la creencia en la bondad del fenómeno en sus variadas formas fue, si se hace caso a estos testimonios de la época, prácticamente generalizada. Sólo en contadas ocasiones se relatan casos fallidos en estos primeros embates y apenas se detectan en las narraciones signos o intentos de fraude ${ }^{25}$.

\section{LOS MÉDICOS SE ASOMBRAN Y ESTUDIAN}

De esta manera, los periódicos médicos extractaron primero las informaciones aparecidas en la presa política nacional y extranjera, reflejando, con un asombro no exento de entusiasmo, la avalancha de ensayos realizados por el vulgo aquellos primeros días de mayo de 1853 sobre el «estrofesomatismo» ${ }^{26}$.

24 DELGRÁs (1853), p. 158.

25 Las menciones a posibles fraudes o bromas en relación con los movimientos de las mesas fueron escasas y del estilo de la siguiente: «Se nos olvidaba decir, y lo decimos entre paréntesis — nos dice el observador de uno de los giros de mesas - que, en los momentos de salto y de movimiento, uno de los operadores había introducido el pie debajo de los del velador, sin duda para activar la acción del fluido, así como la gallina pica el huevo para facilitar la salida del pollo». GUTIÉRREZ DE LA VEGA (1953a), p. 114.

26 El neologismo, formado con dos palabras griegas, una que significa «giro» y la otra «cuerpo», se utilizó ocasionalmente pero acabó por ser olvidado. 
Y el asombro no tardó en generar a continuación un impulso para estudiar la cuestión de una forma más elevada. Para lo cual empezaron recurriendo a los dictámenes y teorías publicados en las publicaciones médicas extranjeras, con las francesas a la cabeza.

No había acabado, así, el mes de mayo cuando aparecieron en los periódicos médicos las referencias a la atención que se prestaba en las instituciones médicas francesas a los nuevos fenómenos ${ }^{27} \mathrm{y}$, sobre todo, los primeros relatos amplios sobre las experiencias llevadas a cabo por médicos con las mesas giratorias. Dos de los más favorables fueron publicados originariamente en el Moniteur des Hôpitaux de París. En el primero de ellos, Raciborski, antiguo jefe de clínica de la Facultad, laureado del Instituto y de la Academia Imperial de Medicina, según reza al final de su comunicación, hacía público el 2 de mayo el siguiente cuidado experimento, efectuado en compañía de otras cinco personas:

«Colocamos en medio de mi gabinete (...) una mesita de roble tallado, de 45 centímetros de diámetro, cuyo pie torcido terminaba en un trípode sin ruedas. Yo mismo coloqué a cuatro de estos señores alrededor de la mesita, de manera que no se tocase su ropa, ni tocasen ellos tampoco a la mesa con los pies. Estas cuatro personas tocaban solamente la superficie de la mesa con las yemas de los dedos, de los cuales el quinto de apoyaba en el dedo correspondiente del compañero inmediato, formando de esta suerte una cadena no interrumpida (...) Al cabo de $20 \mathrm{mi}-$ nutos algunos actores principiaron a experimentar ligeros sacudimientos en los dedos y después hormigueos en los brazos. A los 40 minutos se percibió por primera vez un ligero movimiento de rotación, seguido de otro pasados 2 minutos, y luego de otro, y así sucesivamente, siendo los intervalos cada vez más cortos, en términos que en 8 ó 10 minutos de tiempo presenciamos un movimiento de rotación no interrumpido, una especie de vals, acompañado de un ruido que provenía del roce del trípode contra el entarimado. Este movimiento se verificaba de sur a norte y de izquierda a derecha. Habiendo sobrepujado a nuestras esperanzas este resultado, quise yo que lo presenciase uno de mis clientes, la señora condesa de Chavagnac (...), que me dispensó el honor de concurrir al experimento con cuatro caballeros de su familia. Cosa de 2 minutos después de la entrada de estas personas en mi gabinete, la mesa suspendió su movimiento rotatorio, pero este no tardó en reaparecer,

27 «El martes último se hallaban llenas de experimentadores, en la Academia de Medicina, la sala de la Biblioteca y la de Pas-Perdus (...) los sombreros, sortijas y llaves daban vueltas con más o menos éxito, según la voluntad mentalmente expresada». GUTIÉRREZ DE LA Vega, J. (1853b), «El magnetismo en brazos de la ciencia», El Heraldo Médico, 26 de mayo de 1853, 117-119; p. 119. 
cesando sólo en el momento en que los actores deshicieron la cadena, levantando los dedos de encima de la mesa $»^{28}$.

El segundo experimento, enviado al Moniteur des Hôpitaux con fecha 4 de mayo, venía firmado por A. Hardy, a la sazón agregado a la Facultad de Medicina parisina y médico del Hospital de San Luis, y se resistió en principio a dar resultados positivos. Lo cual parece indicar que las mesas a veces se hacían de rogar y que una cierta experiencia preparatoria y una más que aceptable paciencia favorecía la obtención de movimientos con ellas. En efecto, Hardy intentó primero, formando cadena con su mujer y una hija pequeña, hacer girar una pesada mesa de madera, sin que sus deseos se vieran realizados. Lo ensayó a continuación con las mismas personas pero tomando un sombrero como objeto y esta vez los resultados fueron satisfactorios, pues el sombrero efectuó varios círculos más o menos grandes. Ya por la noche, en casa de unos amigos, Hardy repitió los giros de sombreros con cadenas más nutridas $\mathrm{y}$, alentado por los fructuosos efectos de sus esfuerzos, experimentó de nuevo con una mesa, esta vez con éxito:

«A tal efecto elegimos una cuadrada, de caoba, de cuatro pies y ruedas, llamada mesa de té. Nos colocamos seis personas alrededor de ella, tres hombres y tres mujeres. Ya habían pasado treinta minutos, y ya empezaban a cansarse testigos y actores, pedí algunos minutos de paciencia y, en el momento en que iba a suspenderse el experimento a causa del cansancio, pues iban transcurridos 36 minutos, la mesa se agitó y giró, primero lentamente y después con gran rapidez; cambiamos el orden de superposición de los dedos y el movimiento de rotación se verificó igualmente en la dirección opuesta, cesando sólo cuando se quitaron de la mesa las manos ${ }^{29}$.

Las referencias positivas sobre las mesas giratorias de los médicos franceses fueron, como puede verse en estos dos casos, bastante moderadas, pues sólo consideraban los movimientos giratorios y no mencionaban los fenómenos más extraordinarios, como las danzas de las mesas o la telegrafía psíquica por medio de los golpes de las patas.

Pero, además de las favorables, la prensa médica española también recogió experiencias escépticas de los medios médicos franceses. Una de ellas fue la firmada por H. de Castelnau, aparecida originariamente en la Gazette Médicale de Estrasburgo, en donde se afirmaba que:

28 Ibídem, p. 118.

29 Ídem. 
«...He hecho, pues, experimentos en las condiciones más favorables en apariencia; en uno de ellos he permanecido con tres personas benévolas por espacio de sesenta y cinco minutos en torno de un ligero velador de ruedas, de caoba, puestos sobre una tarima, y os confieso ingenuamente que ni yo ni mis compañeros de experimento hemos visto ni sentido nada» ${ }^{30}$

Por otro lado, aunque algunos médicos proclives a las mesas giratorias, como era el caso de Raciborsky y Hardy, sostenían, a modo de explicación del fenómeno, la existencia de algún tipo de fuerza interna del organismo con efecto no sólo en él sino también fuera de él y, por tanto, sobre los objetos situados en contacto con él o a su alrededor ${ }^{31}$, la mayor parte de los médicos propicios a estos movimientos optaron por explicaciones más naturalistas, achacándolos a algún tipo de impulso involuntario que pasaba desapercibido y que los experimentadores comunicaban a pesar suyo al objeto de experimento.

El predominio de esta última interpretación se debió a un informe emitido por la Académie des Sciences de París sobre la naturaleza de las mesas giratorias en el que se negó, no la rotación, considerada como un hecho real, sino su atribución a los fluidos eléctricos, al magnetismo o a la voluntad ${ }^{32}$. El informe estuvo inspirado principalmente por el químico Michel Eugène Chevreul (1786-1889) y su gestación nos la dejó escrita el propio Chevreul en su libro escrito a raíz del informe académico ${ }^{33}$. El 21 de marzo de 1853 la Academia de las Ciencias nombró una comisión, formada por tres miembros: Chrevreul, el químico Jean Baptiste Boussingault (1802-1887) y el físico Jacques Babinet (1794-1872), para examinar una memoria de un tal Riondet titulada «Sur la baguette divinatoire employée à la recherche des eaux souterraines». Como Chevreul había escrito en 1833 un pequeño trabajo sobre las causas del

30 Ibídem, p. 117.

31 «En vista de un hecho de tal naturaleza, nos vemos obligados a admitir en el hombre afirmaba Raciborski- la existencia de una fuerza, de un poder dinámico, que nace del mismo organismo, y cuya influencia puede ejercerse sobre los objetos que le rodean, y recíprocamente. La naturaleza de esa fuerza nos es desconocida; pero el negarla, sería negar la evidencia». Ibídem, p. 118.

32 M. D. (1853a), «Nuevo descubrimiento magnético», Boletín de Medicina, Cirugía y Farmacia, 29 de mayo de 1853, 174-75: p. 175.

33 Chevreul, M. E. (1854), De la baguette divinatoire, du pendule dit explorateur et des tables tournantes, au point de vue de l'histoire, de la critique et de la méthode expérimentale, Paris, Mallet-Bachelier, pp. 1-2 [Existe una reciente traducción española: CHEVREUL, M. E. (1982), De la varilla adivinatoria, del llamado péndulo explorador y de las mesas giratorias desde el punto de vista de la historia, de la crítica y del método experimental, Barcelona, Humanitas]. 
movimiento de la varilla adivinatoria y del péndulo ${ }^{34}$, sus dos colegas encargaron a Chrevreul la redacción del informe. El mes siguiente comenzó la fiebre de las mesas giratorias y le fue remitida a la Academia para su examen una carta firmada por un tal Kaeppelin sobre esta cuestión y titulada «Influence de l'action vitale et même de la volonté sur la matiére inerte». Dado la similitud que parecía tener el movimiento de las mesas con el de la varilla y el del péndulo, Chrevreul fue de nuevo el encargado de este informe ${ }^{35}$.

Chevreul en su carta a André Marie Ampère (1775-1836) había interpretado el movimiento de la varilla adivinatoria y del péndulo como fruto de dos cosas: de «movimientos musculares insensibles» o involuntarios, primero, y de una cierta «disposición o tendencia al movimiento», después:

«Cuando sostenía el péndulo en la mano, un movimiento muscular de mi brazo, aunque insensible para mí, hizo salir al péndulo del estado de reposo y, una vez iniciadas, las oscilaciones fueron rápidamente incrementadas por la influencia que la vista ejerció para situarme en ese estado especial de disposición o tendencia al movimiento. Ahora es preciso admitir muy claramente que el movimiento muscular, aun cuando esté acrecentado por esta misma disposición, es, no obstante, lo bastante débil para detenerse, no ya bajo el imperio de la voluntad sino cuando se tiene simplemente la intención de probar si tal o cual efecto lo detendrá. Hay pues una estrecha e íntima conexión establecida entre la ejecución de ciertos movimientos y el acto del pensamiento en relación en relación con los mismos, aunque este pensamiento no sea todavía de ninguna manera la voluntad que gobierna a los órganos musculares. En eso consiste el que los fenómenos que acabo de describir me parezcan de algún interés para la psicología e incluso para la historia de las ciencias; prueban cuán fácilmente se pueden tomar las ilusiones por realidades» ${ }^{36}$.

34 Chevreul, M. E. (1833), «Lettre à M. Ampère sur une classe particulière de mouvements musculaires», Revue des Deux Mondes, 2a serie, II, 258-266. El trabajo se volvió a imprimir en CHEVREUL (1854), pp. 154-167.

35 De hecho, la prensa política y médica francesa mencionó la carta de Chevreul a Ampère como muy aplicable para la explicación de los fenómenos de movimientos circulares acaecidos en esos momentos con las mesas. La prensa médica española también se hizo eco de esta aplicación y recogió amplios extractos de la carta: GUTIÉRREZ DE LA VEGA (1853b), p. 117. La prensa francesa recogió las discusiones de la Academia motivadas por las mesas giratorias. Extractos de las mismas se plasmaron también en la prensa médica española: M. D. (1853a), p. 175; y B.-A. de G. y A., J. (1853), «Nuevos experimentos y observaciones sobre el magnetismo animal», Boletín de Medicina, Cirugía y Farmacia, 14 de agosto de 1853, 259-260; p. 259.

36 Chevreul (1854), pp. 157-158. 
Y de forma idéntica interpretó en 1853, apoyándose en las experiencias de Michael Faraday (1791-1867) ${ }^{37}$, los movimientos giratorios de las mesas: como resultado de ese estado particular denominado disposición o tendencia al movimiento que llevaba a aumentar y a continuar un movimiento empezado por contracciones musculares involuntarias ${ }^{38}$. De esta manera, cuando un cierto número de personas se hallaba alrededor de una mesa con sus manos situadas encima, trascurrido cierto tiempo, cundía el cansancio y alguno de ellos hacía un movimiento involuntario, primero vago y luego de forma más determinada, en dirección lateral a la mesa. Por la tendencia al movimiento, ese sujeto continuaba el movimiento lateral. Y, por la misma tendencia al movimiento, los demás partícipes efectuaban acto seguido, por imitación, ese mismo movimiento lateral. Principiaba así la ronda, lenta al principio, y luego cada vez más veloz, que sólo se detenía cuando los participantes levantaban las manos del objeto girante.

Chevreul interpretó del mismo modo los movimientos de las mesas golpeadoras o parlantes: por el desencadenamiento de movimientos involuntarios en alguno de los partícipantes, que hacen que éste de golpes en uno de los pies de la mesa:

«Así (...) concibo el cómo y el porqué una pregunta dirigida a una mesa despierta en la persona que actúa sobre la misma, sin que se de cuenta, un pensamiento cuya consecuencia es el movimiento muscular capaz de hacer golpear uno de los pies de la mesa, conforme el sentido de la respuesta que parece más verosímil a esa persona» ${ }^{39}$.

Pero sólo en parte, pues no intentó explicar otras «manifestaciones espirituales» de las mesas por considerar que se hallaban fuera de su campo científico ${ }^{40}$.

37 Ibídem, pp. 219-223. Faraday ideó una serie de pruebas de control que probaron que la acción que había puesto en movimiento las mesas procedía de las manos. La más conocida fue la colocación de unas láminas de cartón, pegadas ligeramente con masilla entre sí, debajo de las manos de los partícipes. Cuando el movimiento de la mesa se hubo efectuado, Faraday comprobó que había habido un desplazamiento mayor en el cartón superior que en el inferior, de forma que la mesa se había movido después de los cartones y estos después de las manos. Faraday dio a conocer sus experimentos, primero en una carta al Times de Londres, publicada el 30 de junio de 1853, y luego, más detalladamente, en el Athenaeun, en el número del 2 de julio de 1853. Cf.: Crabtree (1993), p. 244; y BlaCKMORE (1994), p. 972.

38 Ibídem, pp. 214-223.

39 Ibídem, p. 224.

40 «Que se recurra a los espíritus para hacer girar las mesas, para contar las bujías o las lámparas de un salón o el número de monedas; para pedirles la hora, el día del mes, la edad de 
Pues bien, como se decía más arriba, fue esta interpretación de Chevreul y, por ende, de la Academia de Ciencias parisina, la seguida principalmente por los médicos franceses que obtuvieron resultados positivos en sus investigaciones con las mesas giratorias, aunque casi siempre aportaban pequeñas variaciones al sistema de fuerzas dual de Chevreul. Esta circunstancia se deja ver también en los trabajos que la prensa médica española recogió de sus colegas franceses. Así, en uno firmado por L. Corvisart el 6 de mayo y aparecido primeramente en el Moniteur des Hôpitaux, se modificaban ligeramente los movimientos insensibles de Chrevreul por «temblores vibratorios rápidos» o temblores continuos de cada una de las fibras microscópicas musculares ${ }^{41}$, siendo estos temblores los que desencadenaban la tendencia al movimiento. Y en otro, firmado por Piégu el 13 de mayo y aparecido originariamente en la Union Médicale parisina, la disposición al movimiento se desataba por tres tipos de fuerzas: las contracciones musculares involuntarias de Chevreul; las contracciones musculares involuntarias que resultan fruto específico del cansancio muscular originado por una tensión prolongada; y los movimientos oscilatorios determinados por la fuerza aórtica del corazón y que pertenecen a la dinámica vascular ${ }^{42}$.

\section{LOS MÉDICOS EXPERIMENTAN}

Así, pues, en este contexto de entusiasmo popular por las mesas giratorias y parlantes, atemperado por las consideraciones más moderadas procedentes de la medina francesa, de las cuales se hicieron incluso balances provisiona$\operatorname{les}^{43}$, los médicos españoles comenzaron a experimentar por sí mismos, inten-

las personas, la conducta a observar o el partido a tomar en una circunstancia dada, el régimen más favorable a un enfermo; que se les consulte sobre las ciencias, las artes, la política, la economía de las sociedades y la teología, todo eso son cosas fuera de nuestro dominio que debo abstenerme de discutir». Ibídem, p. 224.

41 GutiÉrReZ DE LA VEGA (1853b), p. 118.

42 PIÉGU, - (1853), «La fisiología, la física y las mesas giratorias», El Heraldo Médico, 9 de junio de 1853, 125-126; p. 125.

43 «Cuando la discusión se halle más avanzada y se aclare un poco la confusión que las primeras impresiones han causado, procuraremos hacer un extracto de todo cuanto se haya dicho, limitándonos a decir hoy por lo que respecta a la prensa médica francesa: que once de sus periódicos son los que hasta ahora hemos visto que se ocupen del nuevo fenómeno; que, de los once, cinco creen firmemente en la realidad y novedad de él; cuatro dudan, no de la realidad del hecho, sino de su novedad e importancia científica; y dos, en fin, lejos de creer en la existencia del fenómeno, tratan de charlatanes a los que lo intentan realizar, y de ilusos a los 
tando pasar así la cuestión, como se decía en los artículos que fueron publicando, del «dominio público al terreno de la ciencia» y se dispusieron a «precisar los hechos, a apreciar su importancia, a estudiar sus diversas fases y condiciones y hasta a procurar explicarlos con más o menos acierto» ${ }^{44}$. Y no fueron pocos los que así obraron, pues, según las palabras que encabezaban uno de los artículos publicados por entonces, «este nuevo y sorprendente fenómeno, después de haber preocupado por algunos días la atención del público, ha venido a ser objeto del estudio y sabias elucubraciones de la ciencia; por manera que apenas hay un periódico de medicina y demás ciencias naturales que no se ocupe de él con más o menos extensión» ${ }^{45}$.

Los experimentos médicos se centraron fundamentalmente en las rotaciones y dejaron muy en segundo plano los aspectos parlantes de las mesas. Tendieron a seguir, además, un patrón ideal: daban de entrada el nombre y actividad de los partícipes a modo de garantía y a continuación procuraban abarcar tres tipos de experiencias: primero con mesas; luego con otros objetos, especialmente sombreros; y por último con personas. Un buen ejemplo de esta sistemática lo ofrece el realizado por Francisco Castellví y Pallarés en Tortosa, del que da cuenta en una carta enviada a El Heraldo Médico el 8 de junio, y que tiene además la peculiaridad de describir los efectos de la cadena magnética sobre la persona por experiencia propia, ya que fue él mismo el que actuó como objeto de los giros. Constata Castellví en primer término, por tanto, los participantes en el evento más destacados: un canónigo, un teniente coronel y un colega del narrador y, acto seguido, relata los tres momentos experimentales:

« $1^{\circ}$ Formando cadena sobre una pequeña mesa redonda de caoba, sostenida en su centro por un solo pie, no pudimos hacerla girar, sin embargo de haber permanecido más de veinte minutos las siete personas que formábamos la cadena; sólo hizo un movimiento de izquierda a derecha casi imperceptible. Teníamos motivo para dudar de la influencia de cierta persona de las experimentadoras; $y$, en efecto, tan pronto como ella se separó, no se hicieron esperar los movimientos ondulatorios y luego giratorios de izquierda a derecha (...)

$\ll 2^{\circ}$ Hicimos entre tres hombres cadena sobre un sombrero colocado en dicha mesa, y a los tres minutos principió a girar también de izquierda a derecha, tomando a las pocas vueltas tal velocidad, que casi no podíamos seguirlo. Cambiamos la

que creen en él». M. D. (1853b), «Mesas giratorias», Boletín de Medicina, Cirugía y Farmacia, 12 de junio de 1853, 190; p. 190.

44 M. D. $(1853$ a), p. 174. 
cadena, y al momento paró el sombrero como un minuto, girando después en dirección opuesta (...)

$\ll 3^{\circ}(\ldots)$ Formaron al punto cadena a la altura de mi pecho (...) Yo me propuse firmemente no dar vueltas y resistir cuanto me fuera posible. Sin embargo, a los tres minutos, sentí en lo interior de vientre y pecho como la presencia de un eje vertical alrededor del cual se me soplaba ligera y agradablemente de izquierda a derecha; luego experimenté una sensación de ligereza en todo mi cuerpo, y un bien percibido movimiento en la dicha dirección, que no pude contener con todos mis esfuerzos; entonces exclamaron a una voz mis cuatro experimentadores: 'Ya se mueve V.' Efectivamente, no hubo más remedio que permitir a las piernas, ya torcidas por mi resistencia, que siguiesen las vueltas del tronco. No sé cuántas di; pero es lo cierto que por momentos me sentía arrastrar con más velocidad. Cambian la cadena, me paro menos de un minuto, y luego, experimentando las mismas sensaciones, principio a girar en dirección opuesta...» ${ }^{46}$.

Los experimentadores médicos idearon también procedimientos y aparatos para que los giros se produjeran con mayor facilidad y brevedad, dado que lo habitual era que estos fenómenos tardaran muchos minutos y aun horas en producirse, dando lugar al incremento de la incredulidad en todos aquellos que carecían de la necesaria perseverancia.

Uno de los procedimientos - que debió de ser todo un espectáculo digno de contemplación - fue el de la aplicación conjunta de la nariz y los meñiques en la cadena magnética, propuesto por José de Alarcón y Salcedo, licenciado que ejercía a la sazón en la localidad toledana de Alcabón, y del que dio noticia El Heraldo Médico:

«...si quieren verse más rápidos y prontos efectos en la rotación de las mesas y de los hombres, aplíquese a ellos la nariz al mismo tiempo que los meñiques y, aunque la posición es ridícula y cansada, la prontitud del efecto compensará a todo (...) Cualquiera que sea el sitio donde la nariz se coloque entre las manos, la rotación sigue siempre la dirección marcada por la clase de cadena que los meñiques forman» ${ }^{47}$.

46 Castellví y Pallarés, F. (1853a), «Fenómenos magnéticos», El Heraldo Médico, 21 de julio de 1853, 149-150; p. 150. Para más relatos de experimentos llevados a cabo por médicos, véase: RAmos y Borguella, F. (1853), «Nuevo descubrimiento magnético», Boletín de Medicina, Cirugía y Farmacia, 15 de mayo de 1853, 158-159, pp. 158-159; ANÓNIMO (1853), p. 117; y AlarCón y SAlCedo, J. de (1853a), «Baile de las mesas», El Heraldo Médico, 16 de junio de 1853, 129-131; p. 130.

47 AlarCón y SAlCEDO, J. de (1853b), «Fenómenos magnéticos. Movimientos giratorios de los cuerpos y baile de las mesas», El Heraldo Médico, 22 de septiembre de 1853, 185-187; p. 186. 
En cuanto a los aparatos, uno de los que mayor popularidad pudo haber cobrado, a tenor de las referencias que hay de su uso ${ }^{48}$, fue el de Delgrás, expuesto en el Boletín de Medicina, Cirugía y Farmacia:

«El aparato consiste: $1^{\circ}$ en una mesa o banqueta de cortas dimensiones para que permita girar en derredor de ella a los operadores; $2^{\circ}$ en un vaso de cristal bien enjuto de toda humedad; y $3^{\circ}$ en una tabla redonda de poco peso y de un pie a pie y medio de diámetro, como por ejemplo la tapa de una de esas cajas de mazapán que vienen de Toledo, que es precisamente el objeto de que nos hemos servido. Para armar el aparato, basta colocar el vaso boca abajo en el centro de la mesa o banqueta poniendo sobre la tabla redonda en disposición que guarde equilibrio. Hecho esto, forman la cadena consabida sobre los bordes de la tabla tres personas, de las cuales conviene que una sea mujer, y no pasan dos minutos sin que la tabla empiece a girar sobre el vaso en la dirección marcada por los dedos pequeños, arrastrando en su movimiento a los operadores» ${ }^{49}$.

Pero los médicos y farmacéuticos no se contentaron pergeñar nuevos procedimientos y aparatos para mejorar los experimentos habituales llevados a cabo con las mesas giratorias. A veces fueron más allá y algunos llegaron a establecer nuevos planteamientos, nuevas formas de experimentación, en relación con los movimientos de las mesas que hicieron entrever las posibilidades que encerraban estos fenómenos. Ejemplares a este respecto fueron los ensayos realizados por el farmacéutico del Hospital General de Tarragona José María Pelegrí, aparecidos en el Boletín de Medicina, Cirugía y Farmacia y que también recogió Mariano Cubí (1801-1875) en las notas del capítulo dedicado a las mesas giratorias de su libro La frenología y sus glorias ${ }^{50}$. El método seguido por Pelegrí fue muy cauteloso. Primero fue introduciendo pequeñas modificaciones en los experimentos habituales, como los cambios de dirección del giro independientemente del tipo de cadena magnética, de primera o de segunda especie, utilizada; o el aumento de peso progresivo de la mesa objeto de estudio a fin de ver los posibles efectos sobre el giro:

«Varios sujetos dotados de la impasibilidad necesaria se aproximaron a una mesa velador que gira sobre su pie, e hicieron la aplicación de las yemas de los dedos con toda delicadeza, formando entre sí la cadena, y a los pocos minutos comenzó a moverse la mesa (...) En tal estado previne que todos ellos formasen fir-

48 Véase: M. D. (1853b), p. 190.

49 DELGRÁs (1853), p. 157.

50 CuBí Y SOLER, M. (1853), La frenología y sus glorias: lecciones de frenología, Barcelona, Imprenta Hispana, pp. 1003-1006. 
me y sostenida voluntad de que cambiase la dirección del movimiento y la mesa seguía por cortos momentos en su movimiento primitivo, hasta que, vencida por la inercia, se para un poco la mesa y comienza sin notable dilación el movimiento giratorio inverso con mucha más fuerza que el que tenía antes. Repetimos varias veces el experimento, con la circunstancia de hacer subir sobre el velador un niño de 10 años, y no por eso dejó de girar del mismo modo; luego subieron personas de más peso, hasta las hubo de más de nueve arrobas, sin que ese enorme peso fuese obstáculo al movimiento giratorio del velador, que lo verificaba a derecha o a izquierda, según era la voluntad de los operantes. El experimento se ha repetido muchas veces en diferentes días y por distintas personas, dando siempre igual resultado, sea que se formase la cadena de $1^{\mathrm{a}}$ o de $2^{\mathrm{a}}$ especie, o que se colocasen los dedos meñiques caprichosamente (...); de suerte que el movimiento giratorio de la mesa u otro objeto pende más de la uniforme voluntad de las personas que se aplican a la formación del fenómeno, que de cualquiera otra fuerza o elemento... $\rangle^{51}$.

Y, posteriormente, una vez allanado y afirmado así el terreno, realizó otros ensayos con las mesas totalmente novedosos, como es éste que viene a continuación, en el que se establece una especie de duelo magnético de voluntades:

«En medio de estas operaciones, dos individuos ya prácticos en el modo de dirigir la voluntad, se colocaron en el velador uno frente de otro o diametralmente opuestos, y aplicaron las manos en el borde como cuando se formó la cadena, pero sin contacto entre sí (...); previne que formasen voluntad de que velador girase por la derecha y lo lograron sin dificultad. Visto por mí que dos individuos solamente bastaron para hacer girar la mesa según su voluntad, previne que se animasen de voluntades opuestas, queriendo el uno que la mesa girase por la derecha y otro por la izquierda, y fue el resultado la neutralización de las voluntades y, en consecuencia, la inacción de la mesa (...); me apliqué yo a la mesa proponiéndome emplear mi firme voluntad en favor de uno de los dos: a poco rato dio un crujido la mesa y muy luego se puso en movimiento por el lado apetecido por las dos voluntades (...) Estos últimos experimentos los he repetido también varias veces con diferentes personas, resultando en unas neutralización de voluntades y, en consecuencia, inmovilidad de la mesa, y en algunas otras, ya sea fuesen poco prácticas en el modo de dirigir la voluntad o que el poder de ésta fuese inferior al mío, vencí en la lucha y el velador giró por el lado que yo dirigía la voluntad» $»^{52}$.

Todos estos experimentos protagonizados por médicos que, primero, se limitaron a remedar los ensayos iniciales del vulgo aunque de forma más pautada y ordenada; segundo, fueron luego hechos con nuevos procedimientos y

51 Pelegrí, J. Ma., «Mesas giratorias», Boletín de Medicina, Cirugía y Farmacia, 24 de julio de 1853, p. 239; p. 239.

52 Ídem. 
aparatos en pro de una mayor agilidad y facilidad en su realización; y, tercero, sirvieron finalmente para introducir nuevos planteamientos y formas de abordaje originales de los fenómenos giratorios con objetos y personas, generaron una serie de conclusiones que complementaron y mejoraron aquellas que se hicieron en la prensa política y de opinión en los primeros días de la moda de las mesas. Entre estas nuevas hay que destacar las siguientes: que los movimientos podían originarse sin que los participantes formaran cadena con sus manos, siendo diversas las posturas que éstas podían tener sobre los objetos o las personas girantes; que la voluntad y el deseo de todos los concurrentes al experimento era de principal importancia para la pronta y fácil manifestación del fenómeno; que cuando entre ellos había alguno que se resistía, ya fuera por incredulidad o por ánimo deliberado en contra, la manifestación del fenómeno o no se verificaba o lo hacía con mucha dificultad; que hecho el experimento entre dos personas que tuvieran una voluntad opuesta entre sí en relación con la dirección del movimiento o bien la mesa permanecía inmóvil o bien tomaba la dirección preconizada por el individuo de voluntad más enérgica; y que no había necesidad alguna de cambiar la posición de los dedos para variar la dirección de los giros, bastando sólo la voluntad del operador, si era único, o la unánime, cuando eran más de uno ${ }^{53}$.

\section{LOS MÉDICOS EXPLICAN}

Como se desprende de la lectura de estas conclusiones, a diferencia de la francesa, la prensa médica española, se mostró más proclive en principio a las explicaciones «fluidistas» y poco partidaria de las «muscularistas» de Faraday, Chevreul y de la Academia de las Ciencias que consideraban el fenómeno de las mesas giratorias resultado de movimientos musculares que pasaban desapercibidos ${ }^{54}$.

Uno de los escasos secuaces entre nosotros de esta segunda forma de pensar que dejó constancia de ello en la prensa médica fue Carlos Lúcia, de la localidad castellonense de Segorbe. En una amplia carta enviada el 21 de mayo al Boletín de Medicina, Cirugía y Farmacia, Lúcia señaló primeramente

53 Cf.: Delgrás (1853), p. 158; M. D. (1853), p. 175; y Nieto, - (1853), «Movimiento giratorio comunicado por contacto», Gaceta Médica (de Madrid), 20 de mayo de 1853, 113116; p. 114.

54 El término «muscularista» pertenece a Cubí, muy dado al empleo de neologismos. CUBÍ Y SOLER (1853), p. 1004. 
su experiencia con el sencillo aparato de Delgrás, constatando la rápida aparición de los fenómenos giratorios: «Desde luego convengo con Vds. en la realidad del hecho: la tabla redonda rueda sobre el vaso a los pocos minutos de aplicarle las yemas de los dedos ${ }^{55}$. A continuación, pasó a analizar el fenómeno de forma concisa, pero muy meticulosa y esclarecedora:

«Vds. han observado, y yo les he secundado en su observación, que ni la naturaleza del objeto, ni su figura, tienen una influencia decisiva en el éxito del experimento: rueda lo mismo una tabla redonda, que un libro, un plato, etc., con tal de que la disposición en que se coloque le permita rodar a un ligerísimo impulso. Tampoco es condición necesaria el aislamiento del objeto, ni la forma de la cadena; porque yo he visto rodar la tabla colocada sobe cualquier objeto que la permita rodar, y aplicando los dedos sin formar dicha cadena. Es igualmente indiferente que las personas que aplican los dedos estén o no en contacto entre sí (...). Estos hechos (...) no favorecen la admisión de un fluido parecido al eléctrico y magnético. Hay más: para que la rotación tenga lugar, es condición indispensable que los dedos toquen bien la tabla; no basta que estén en el contacto imperceptible que produce la transmisión de los fluidos imponderables (...); y la fuerza con la que rueda es tan pequeña que se le detiene con el más ligero obstáculo» ${ }^{56}$.

\section{Y, por último, llega a unas conclusiones muy en razón:}

«Todos estos hechos me hacen pensar por ahora: que el movimiento procede del impulso que involuntariamente transmiten al objeto las personas que hacen el experimento; y por eso es necesario que los dedos toquen de modo que puedan comunicar el movimiento pulsatorio. Que se acelera la rotación a beneficio de la falta de quietud que produce el cansancio y del mismo hecho de rodar las personas para seguir a la mesa; las cuales, a su pesar, han de comunicar algún impulso, al andar, al cuerpo con que están en contacto. Por último, que no es absolutamente necesario, para la producción de los hechos reconocidos, la influencia del fluido magnético que se pretende con ellos demostrar, toda vez que pueden ser un efecto complejo de las causas indicadas $»^{57}$.

Si Lúcia negaba la causa fluidica por el análisis de la calidad del movimiento rotatorio, otros autores, como fue el caso de Manuel Aguirre e Iriepar, licenciado del pueblo madrileño de Barajas, en carta fechada el 22 de junio, suscribieron también las teorías de Chevreul basándose en la incomunicabilidad de los fluidos, cualquiera que fuese su índole, de nuestro organismo a los cuerpos inorgánicos:

55 M. D. (1853b), p. 190.

56 Ídem.

57 Ídem 
«hallándose explicados estos fenómenos por la acción o ejercicio de nuestros órganos, seria innecesario (...) quererlo atribuir a la influencia de éste u otro fluido, porque, si fuera el eléctrico, el galvánico o el magnético su verdadero agente, sería necesario empezar por admitir que en nuestra economía existe la facultad de engendrarlos y comunicarlos a nuestro arbitrio, lo que no me parece muy conforme a la razón (...) Pues, si ninguno es de estos, ¿lo será el nervioso? De un modo (...) directo no; porque el fluido nérveo no puede (...) transmitirse a los cuerpos inorgánicos; pertenece exclusivamente a los organizados mientras les dura la vida; además que éste sólo ha podido ser admitido hipotéticamente, comparándole con el galvánico, para explicar los resultados de la acción nerviosa...» ${ }^{58}$.

Con todo, a pesar del aparente tino de estos argumentos, la opinión mayoritaria de los médicos patrios se inclinó en esos meses de euforia hacia el fluidismo. Para lo cual tampoco faltaron argumentos. En contra de los propuestos por Lúcia se adujo: que los giros no sólo se producían con objetos livianos, como los que él había estudiado, sino también con cuerpos voluminosos y de mucho peso; que, en ocasiones, las mesas se levantaban completamente del suelo con el solo contacto de las puntas de los dedos sobre su superficie; y que además, y sobre todo, el experimentador relataba siempre una sensación inconfundible que no dejaba dudas de la fuerza del fenómeno (imposible de alcanzar por meras contracciones musculares esporádicas) y que se ponía de manifiesto en la velocidad que a veces acababan adquiriendo las rotaciones ${ }^{59}$.

Y para rebatir lo sostenido por Aguirre se recurrió a diversas variantes de la llamada «teoría de la emanación», muy extendida entre los afines al magnetismo animal, según la cual el fluido magnético o nervioso elaborado por el organismo podría emanar fuera del propio sujeto por intermedio de su voluntad, produciendo así efectos en otras personas o cosas. Siguiendo esta dirección, Alarcón y Salcedo, en la carta enviada a El Heraldo Médico para relatar sus experiencias y elucubraciones en relación con los mesas giratorias, afirmaba que: «....algo escapa por la punta de los dedos... y bien se concibe que, si hay fluido nérveo o zoomagnético, puede y debe ser él mismo ese algo» ${ }^{60}$.

58 Aguirre e Iriepar, M. (1853), «Fenómenos magnéticos», El Heraldo Médico, 28 de julio de 1853, 153-154; p. 154.

59 M. D. (1853b), p. 490.

60 AlarCón y SALCEDo (1853a), p. 186. Uno de los médicos que más había contribuido a divulgar en la medicina española la teoría de la emanación en los años anteriores, y a quien Alarcón cita expresamente en su carta como referencia principal, fue Ramón Comellas. Exponiendo esta teoría en su pequeña obra sobre el magnetismo animal, Comellas sostenía que «la 
Dado ese sesgo fluidista mayoritariamente visible en la prensa médica al menos hasta el término de 1853, no es raro leer en ella explicaciones sumarias de los fenómenos giratorios al final de las contribuciones del estilo de las de Alarcón («...estos fenómenos son debidos a la existencia en nosotros de corrientes continuas de un fluido semejante a la electricidad o al galvanismo, que ponemos en movimiento a nuestra voluntad y que es el llamado fluido nérveo o zoomagnético» ${ }^{61}$ ) o de las de Pelegrí («...a fuerza de voluntad se exprime (...) este fluido eléctrico animal, o magnético, como quieren otros, el que conducido por esa telegrafía nérvea de que está revestido todo nuestro cuerpo, produce los fenómenos indicados, a la manera que con la sola voluntad movemos un brazo y no el otro, una mano y no el pie» ${ }^{62}$ ). El fluido escapaba, por tanto, del organismo, se incorporaba a otros cuerpos inorgánicos (mesas, llaves, palanganas, libros...) u orgánicos (otras personas) y ocasionaba los efectos rotatorios ${ }^{63}$.

Hacer comprobables de alguna u otra forma estas corrientes o fluidos que escapaban por los dedos entrañaba una cierta dificultad. Por eso sus partidarios acogieron con entusiasmo un curioso aparato que hizo su aparición justo

voluntad pone en movimiento un agente o fluido particular elaborado o acumulado en nuestro cuerpo; dicho fluido, que han llamado magnético, es lanzado por dicha voluntad y va a impresionar al sistema nervioso de la persona a la que se dirige». [COMELLAS, R. (1846), Reseña sobre el magnetismo animal dedicada a los médicos y al público español, Madrid, P. Madoz y L. Sagasti, p. 11]. Comellas a su vez se inspiró a este respecto -y en otros muchos- en Léon Rostan (1790-1866), uno de los neurólogos más prestigiosos de la época, de quien tradujo muy posiblemente su artículo sobre magnetismo de 1825 y publicado en el Dictionnaire de médecine editado por Adelon et al. [Cf.: RostAn, L. (1845), Del magnetismo animal (ed. orig fr. de 1825), trad. esp. (no consta traductor), Valencia, M. de Cabrerizo]. Para la definición de la teoría de la emanación en Rostan, v. las pp. 54-56 de la ed. española.

61 Alarcón y SALCEDo (1853a), p.131.

62 Pelegrí (1853), p. 239.

63 Algunos autores, como Cubí, establecieron ciertas condiciones para que se produjera la incorporación de los fluidos a los objetos o personas externas: «....se desprende de nuestro cuerpo un fluido vital dominado por la voluntad, el cual se incorpora hasta en objetos inorganizados con tal de que se hallen a la vista y en contacto con los dedos del cuerpo humano». CuBÍ Y SOLER (1853), p. 1010. También Juan Bautista de Torres hizo consideraciones parecidas: «Esta fuerza, ¿es transmitida por la mano o por los ojos? Lo ignoro. Lo que sí sé es que deben obrar de consuno la vista, el tacto y la voluntad; que, en faltando una de las dos primeras circunstancias, deja de producirse el fenómeno, y que no antecediendo al experimento una determinada voluntad, se produce sí algún efecto, pero indeterminado». Torres, J. B. de (1853), «Fenómenos magnéticos», El Heraldo Médico, 21 de julio de 1853, 149; p. 149. 
por entonces: el zoomagnetiscopio que un tal Weir había ideado en Estrasburgo ${ }^{64}$. A pesar del nombre tan rimbombante, el zoomagnetiscopio de Weir era algo extremadamente modesto y simple: consistía en un corcho en el que se clavaba una aguja por el ojo y en la punta se colocaba una estrecha tira de papel doblada por la mitad y formando un ligero ángulo con sus extremos de tal forma que se mantuviera en equilibrio. El aparato permitía realizar el experimento siguiente:

«Aproxímese una mano al aparato en la misma forma que se pondría si se quisiera preservar a una luz de la fuerza del aire. A los pocos instantes comienza a moverse el papel con más o menos rapidez, según la cantidad de fluido que posea el experimentador. Si es la mano derecha la que opera, vuelve el papel de izquierda a derecha; y, si la izquierda, gira al lado contrario. Esta operación puede repetirse alternando las manos, pero el resultado es el mismo» ${ }^{65}$.

El artilugio fue considerado por sus defensores como un aparato de sensibilidad exquisita y muy fiable que indicaba y medía la presencia de las corrientes eléctricas, galvánicas, nerviosas o magnéticas que emanaban de los dedos y además permitía ver fehacientemente sus efectos en un objeto externo al organismo ${ }^{66}$.

Por otro lado, si la teoría «muscularista» se apoyaba en las experiencias de Faraday y de Chevreul, la teoría «fluidista» o «voluntarista» también encontró fundamento «internacional», según relata Cubí, en otra serie de experimentos realizados en el Ateneo de Manchester la noche del 2 de junio de 1853, de los que se dio cuenta detallada en el diario local Examiner and Times en su número del 4 de junio. En medio de una gran concurrencia, se formaron en el Ateneo ocho cadenas alrededor de sus respectivas mesas y pasaron a efectuarse a continuación los experimentos habituales, de tal forma que pudieran contrastarse sus resultados en las distintas mesas. Al cabo de los cuales de determinó que:

«...los objetos se mueven sin impulsión muscular, y sólo en virtud de un fluido eléctrico nervioso, transmitido por ellos por el contacto de los dedos y los ojos,

64 GutiÉRrez de LA VeGA (1853b), p. 119.

65 Ídem.

66 Los experimentos más extensos y detallados con el zoonmagnetiscopio reflejados en la prensa médica se encuentran en: AlARCón y SALCEdo (1853a), pp. 130-131. Menciones apreciativas del aparato y sus funciones se localizan también en: B.-A. de G. y A., J. (1853), p. 260; y CASTEllví y PALlARÉS (1853b), «Fenómenos magnéticos», El Heraldo Médico, 18 de agosto de 1853, 165; p. 165. 
como conductores de ese conducido fluido, que se halla bajo el dominio de la voluntad y de las facultades parciales para su comercio activo entre sí, entre sí y el organismo, y entre el organismo y los objetos que lo rodean ${ }^{67}$.

En todo caso, las opiniones no estuvieron en todos los autores tan polarizadas entre el «muscularismo» y el «fluidismo». También hubo posiciones eclécticas que intentaron mal que bien ambas posturas. Nieto fue posiblemente el que expresó con una argumentación más clara esos intentos de concordia:

«Así se vacila entre unas y otra explicaciones o se adopta una de ellas con entusiasmo, desechando las demás por creerlas incompatibles. Mas pudiera suceder que ninguna de ellas comprendiese toda la verdad y que todas la contuvieran en parte. Explanaré esta idea. Las tales explicaciones sólo son hipotéticas en cuanto a su intervención en el fenómeno: por lo demás son hechos indudables. Es muy positivo que el vértigo nos hace mover involuntariamente; que la prolongación de un equilibrio trae la rotura del mismo, como cede un dique a una presión excesiva; que los órganos están animados de un movimiento continuo; que la actividad vital influye visiblemente en los movimientos exteriores y da lugar a la producción de los efectos que se han atribuido a los fluidos calórico y eléctrico; y, por fin, es cierto que el mundo que habitamos tiene una especie de vida particular con agentes imperceptibles y movimientos inmensos. Sentado esto, se sigue forzosamente que todos los hechos referidos (...) pueden tomar parte (...) en el fenómeno de la rotación por contacto, siendo todos capaces de modificarle en algún sentido» ${ }^{68}$.

También hubo intentos de explicación de las fuerzas motoras desde perspectivas más generales y vitalistas y no tan específicamente centradas en las corrientes o fluidos nerviosos, eléctricos o magnéticos, como puede verse en las siguientes palabras del médico de Cabra (Córdoba) Joaquín Quintana:

«Se califica y decora con el nombre de eléctrico, de magnético, el fenómeno del movimiento giratorio. ¿No sería más adecuada la calificación de fenómeno vital y considerar el objeto en movimiento como un órgano suplementario de la organización, bajo cuya impresión táctil se mueve, órgano que aspira a la vida por el contacto con la vida?» ${ }^{69}$.

Y, por último, también hubo, aunque más tardías, incipientes explicaciones espiritistas. Tras las esporádicas menciones a los espíritus asociadas a las

67 Cubí y Soler (1853), pp. 1010-1011.

68 NiETO (1853), p. 116.

69 Quintana, J. (1853), «Movimientos giratorios», Gaceta Médica (de Madrid), 20 de junio de 1853, 141-142; p. 141. 
adivinaciones y mensajes transmitidos por las mesas que aparecieron en la batahola de informaciones de mayo de 1853, tuvo que transcurrir casi un año para que aparecieran las primeras consideraciones extensas en la prensa médica sobre las causas no sólo de los giros sino también de las facultades parlantes de las mesas. Se seguía pensando que ambos tipos de fenómenos eran producidos por los fluidos de los participantes, pero se principió a mencionar - y las sospechas se hicieron tanto más fuertes cuanto más se tenían en cuenta las propiedades parlantes mediante golpes de las mesas- que dichas corrientes fluidicas podrían ser gobernadas por espíritus e incluso por demonios.

La primera noticia de estas características se pudo ver en los diarios médicos en febrero de 1854 en un artículo, bastante confuso, de Castelleví y Pallarés ${ }^{70}$. Pero fue en otro fechado el mes siguiente en donde la preocupación por la causa espiritista se mostró ya más abiertamente ${ }^{71}$. Esta colaboración contenía unas reseñas (aparecidas con anterioridad en la prensa francesa) de la obra de Jules Eudes, marqués de Mirville (1802-1873) sobre las manifestaciones fluidicas de los espíritus, cuyo primer volumen había aparecido en $1853^{72}$. Jules de Mirville exponía ya en él su teoría de que los fenómenos de las mesas giratorias y parlantes y demás manifestaciones supranormales asociadas estaban causados por espíritus y no siempre benéficos, pero se servían para realizarlos del gobierno del fluido magnético de los sujetos presentes.

Las tres reseñas que conformaban esta noticia estaban firmadas por el P. Ventura de Raulica, general de los teatinos, F. de Saulcy, miembro del Instituto de París y el Dr. Coze, decano de la Facultad de Estrasburgo. Y todas eran bastante halagüeñas con la obra de Mirville. Pero lo que aquí más importa es que en ellas se muestra, primero, la progresiva extensión de la creencia de la causa espiritista de las mesas giratorias y parlantes:

«En resumen, creo en la existencia — afirma Saulcy- de ciertos hechos que muchas veces nuestra voluntad no puede producir, y sobre los cuales declaro que la

70 CAStellví y PallarÉs, F. (1854), «¿El estudio de las mesas parlantes conduce al panteísmo?», El Heraldo Médico, 12 de febrero de 1854, 45-46.

71 Raulica, V. de; Saulcy, F.; y Coze, - (1854), «Magnetismo animal», El Heraldo Médico, 16 de marzo de 1854, 81-82.

72 Mirville, J. E., marquis de (1853), Pheumatologie. Des esprits et de leurs manifestations fluidiques, vol I, Paris, H. Vrayet de Surcy. La publicación de los diez volúmenes de que constó finalmente la obra se extendió hasta 1868 y resulta muy dificultosa de seguir, pues aparecieron de forma independiente a lo largo de esos 15 años ý ocasionalmente hizo además suplementos que añadió a los volúmenes publicados previamente. Cf.: CRABTREE (1988), p. 172. 
voluntad ejerce una acción palpable a pesar de todo. Creo en la intervención de una inteligencia diferente de la nuestra y que se pone en actividad por medios casi ridículos» ${ }^{73}$.

Y, segundo, la sensación de peligro que les embarga al contacto con estos manifestaciones extraordinarias ( $\ll$ o estos fenómenos no son positivos, o lo son; si lo primero, es vergonzoso perder en ellos el tiempo; si lo segundo, es peligroso provocarlos y formar de ellos un pasatiempo») ${ }^{74}$. Sensación que aconseja el conjuro de estas manifestaciones mediante la dedicación de la ciencia a su estudio («...estad seguro de que los médicos y los sabios serán los primeros que se convertirán a vuestras doctrinas, y los filósofos irán después», acababa Raulica su critica) ${ }^{75}$. La puerta al necesario abordaje científico del espiritismo comenzaba así a entreabrirse.

\section{LAS REPERCUSIONES DE LAS MESAS GIRATORIAS}

La epidemia psíquica de las mesas giratorias se extendió por España y el occidente europeo desde abril hasta finales del verano de 1853 y durante estos meses, especialmente en los tres primeros, afectó a gran cantidad de gente de todo tipo y condición. Siguió dando coletazos cada vez más débiles hasta los dos primeros meses de 1854 , como se ve en los periódicos médicos ${ }^{76}, \mathrm{y}$, a

73 Raulica; Saulcy; y COZE (1854), p. 82.

74 Ídem.

75 Ibídem, p. 81. A pesar del pensamiento católico de Mirville, los religiosos españoles tuvieron, a diferencia de Raulica, una postura bastante menos connivente con sus postulados. Como diría poco después uno de ellos, cuya opinión también apareció reflejada en las páginas de los periódicos médicos: «...deducir del baile de las mesas el panteismo, argüir a la existencia de ciertos espíritus, trasgos y duendes, inteligencias libres e independientes de los investigadores, esta es una verdadera locura (...), es el producto lógico de una reacción espiritualista». Fray Melitón (1854), El Heraldo Médico, 8 de abril de 1854, 101-102; p. 101.

76 Entre los más significativos de estos últimos artículos se encentran: VÉRGES, A. (1853a), «Fenómenos magnéticos. Interpretación física, fisiológica y metafísica de los fenómenos magnéticos», El Heraldo Médico, 8 de septiembre de 1853, 177; CASTELlví y PALlARÉS, F. (1853c), «Fenómenos magnéticos», El Heraldo Médico, 24 de noviembre de 1853, 221-222; VÉrgES, A. (1853b), «Fenómenos magnéticos. Nuevas pruebas a favor de la rotación de los cuerpos y del movimiento del péndulo», El Heraldo Médico, 22 de diciembre de 1853, 237-238; y AlARCÓN y SALCEDO, J. de (1854), «Fenómenos magnéticos», El Heraldo Médico, 20 de enero de 1854, 21-22. 
partir de ahí, su puesta en práctica quedó progresivamente limitada a los círculos espiritistas y ocultistas.

Su presencia masiva fue, por tanto, fugaz, pero no por ello dejó de originar una serie de repercusiones. Una de ellas fue la llamada de atención que supuso hacia la actividad mental inconsciente y sus efectos. Faraday y Chevreul habían demostrado experimentalmente, considerándolo un fenómeno físico, que podía desarrollarse una fuerza muscular que desplazara las mesas lateralmente sin que se fuera consciente de ello. Pero fueron Braid y Carpenter quienes dieron un giro psicológico a esta perspectiva ${ }^{77}$. Como Faraday y Chevreul, James Braid (1795-1860), cirujano y oftalmólogo escocés y autor de la célebre Neurypnology (1842), rechazó la noción de fluido y a tribuyó el movimiento de las mesas al extraordinario influjo que podían llegar a tener las ideas dominantes en determinados individuos, hasta el punto de producir acciones musculares en consonancia con dichas ideas sin ningún esfuerzo volitivo consciente ${ }^{78}$.

Asimismo, William Benjamin Carpenter (1813-1865), el fisiólogo y naturalista inglés a quien hoy se considera uno de los fundadores de la moderna teoría del inconsciente adaptativo, también llegó, y en la misma fecha, a conclusiones muy similares a las de Braid en relación con las mesas giratorias, pues consideraba que la continuada concentración de la atención en cierta idea la confería un determinado poder, no sólo sobre la mente sino también sobre el cuerpo, de tal manera que los músculos se convertían en instrumentos involuntarios por los cuales se operaban determinadas acciones ${ }^{79}$.

La observación del fenómeno físico de las rotaciones de las mesas llevó así a la noción psicológica de idea dominante, lo cual acabaría provocando la atención sobre por la actividad mental inconsciente ${ }^{80}$.

77 CRABTREe (1993), pp. 244-245 y 254-256.

78 BRAID, J. (1853), «Hypnotic therapeutics, illustrated by cases. With an appendix on table-moving and spirit-rapping», Monthly Journal of Medical Sciences, 17, 14-47; p. 38.

79 CARPENTER, W. (1853), «Electrobiology and mesmerism», Quarterly Review, 93, 501557; p. 547.

80 En los años posteriores, Carpenter, a partir de esta idea de acción involuntaria producida por una idea dominante, elaboraría su noción de «cerebración inconsciente» (unconscious cerebration). La palabra «cerebración» no hacía referencia al pensamiento sino a la acción refleja del cerebro. Con la cerebración inconsciente pretendió explicar las acciones automáticas que parecen ser inteligentes pero que no alcanzan la consciencia del sujeto. Cf.: CARPENTER, W. (1876), Principles of Mental Psychology, with Their Applications to the Training and Discipline of the Mind, and the Study of the Morbid Conditions, $4^{\mathrm{a}}$ ed., London, H. S. King, 
Habida cuenta de la limitada consideración que tuvieron en España las teorías de Faraday y Chevreul, resulta comprensible que esta primera repercusión del fenómeno de las mesas giratorias no dejara eco alguno en nuestro país. Pero sí lo dejó en cambio una segunda repercusión: el auge del magnetismo animal, efecto también comprensible dado ese predominio de lecturas fluidistas que aquí tuvieron los fenómenos rotatorios.

Hay que tener en cuenta que a partir de la década de 1840 el magnetismo animal había experimentado una tardía pero relativamente creciente aceptación en España ${ }^{81}$. Aparecieron por entonces las traducciones de las obras de Jean Joseph Aldolphe Ricard, Alphonse Teste y Aubin Gauthier ${ }^{82}$, todos ellos tratados generales bien elaborados sobre magnetismo animal; se publicaron también trabajos originales de algún interés, como las de Cubí y Comellas ${ }^{83}$; y las notas y artículos sobre magnetismo animal en las publicaciones periódicas médicas fueron menos esporádicas y más encomiásticas.

En este contexto expectante tuvo lugar el episodio de las mesas giratorias y las rotaciones de objetos y personas se tomaron ávidamente, como se ha mostrado más arriba, como una prueba fidedigna de la existencia del fluido magnético y de su capacidad de irradiación fuera de los límites del cuerpo, con las consiguientes posibilidades terapéuticas que eso abría para el magnetismo. El estado de ánimo optimista sobre las capacidades de las prácticas magnéticas se incrementó y esta situación se prolongó durante unos años, como lo indican las siguientes palabras de Joaquín Quintana, tomadas de un amplio artículo aparecido en El Siglo Médico en 1856:

81 Sobre este período de una cierta bonanza del magnetismo animal en España, el cual se extendió desde comienzos de la década de de 1840 hasta finales de la década de los 1850 , véase: GONZÁlez DE PABLO, Á. (2006), «Animal magnetism un Spanish medicine (17861860)», History of Psychiatry, 17, 279-298; pp. 284-288.

82 RiCARD, J. J. A. (1844), Tratado teórico-práctico del magnetismo animal o método fácil de aprender a magnetizar [ed. orig. fr. 1841], trad. esp. de D. A. C. y D. F. D., Barcelona, I. Estivill; TESTE, A. (1845), Manual práctico de magnetismo animal o exposición metódica de los procedimientos para producir fenómenos magnéticos y sus aplicación al estudio y al tratamiento de las enfermedades [ed. orig. fr. 1840], trad. esp. de M. Cubí y Soler y M. Pers y Ramona, Barcelona, J. Verdaguer; y GAUTHIER, A. (1846), Tratado teórico-práctico del magnetismo animal o sea, explicación del magnetismo y de todos los principales procederes empleados por los más célebres magnetizadores [ed. orig. fr. 1845], trad. esp. de I. M. de Villanueva, Barcelona, J. Ribet.

83 Cubí y Soler, M. (1849), «Magnetismo humano», en: M. Cubí y Soler, Elementos de frenología fisonomia y magnetismo hmano, en completa armonía con la espiritualidad, libertad e inmortalidad del alma, Barcelona, A. Gaspar; y COMELLAS (1846). 
«Tratando, pues, la cuestión a la altura de los principio, necesario es convenir, so pena de desconocer las más elocuentes lecciones de la experiencia, que el magnetismo reúne todas las condiciones indispensables para enseñorearse sobre una zona de la patología, más o menos extensa, en relación con la importancia de las perturbaciones vitales (...) Y adviértase que hasta aquí sólo me refiero al magnetismo considerado en sí propio como medio curativo, y de ninguna manera al sonambulismo como origen de las previsiones médicas sorprendentes (...) Colocado en este nuevo punto de vista [en el del sonambulismo], veo ampliarse considerablemente el círculo de las operaciones terapéuticas, y el magnetismo se convierte en un rico tesoro, que en más de una ocasión podrá explotar el médico sabio» ${ }^{84}$.

Pero esta confianza en las posibilidades del magnetismo animal no se mantuvo durante mucho tiempo. Al final de esta misma década sus prácticas comenzaron a declinar visible y definitivamente, y ello debido en parte a la aparición en escena de un procedimiento nuevo pero con el que tenía muchas concomitancias: el hipnotismo.

Por último, la tercera repercusión de las mesas giratorias y parlantes fue el desarrollo del espiritismo en toda Europa, incluida España. Las rotaciones y golpes de las mesas habían sido algo crucial, como se ha recordado en las primeras páginas de este trabajo, en la aparición y desarrollo del espiritismo en los Estados Unidos. Y con su exportación al Viejo Continente en abril de 1853 también lo fueron aquí.

Son legión los testimonios de espiritistas que se refieren a la importancia de esos fenómenos giratorios y parlantes para el espiritismo en Europa. Entre nosotros, puede citarse, por ejemplo, a Blanco Coris y su libro sobre las razones para denominarse espiritista:

«De las manifestaciones espiritistas que más me llamaron la atención al comienzo de mi iniciación, fueron las producidas por las mesas, con sus golpes, levitaciones, crujidos extraños y movimientos circulares y de arrastre, unas veces lentos y tranquilos; otras violentos y fuertes, pero siempre inesperados (...) Más que el abecedario de contestaciones; más que las preguntas y las disquisiciones de los Espíritus, tan frecuentes en las sesiones espiritistas familiares, me preocupaba la movilidad extraña de las mesas (...) He visto destrozarse una mesa a fuerza de golpes violentos y (...) desprenderse el tablero de un velador y caer sobre las piernas de uno de los asistentes. También he observado con sorpresa los movimientos de rotación cónica en la levitación, los bailes acompasados al tararear algún vals, y levantarse solo lentamente, sin imposición de manos, un velador del suelo» ${ }^{85}$.

84 Quintana, J. (1856), «Cuatro palabras sobre el magnetismo animal», El Siglo Médico, 31 de agosto de $1856,273-275 ;$ p. 275.

85 Blanco Coris, J. (s. a.), Por qué soy espiritista. Estudio crítico doctrinal sobre la sugestión y el espiritismo, Barcelona, Maucci, pp. 40-42. 
A pesar de esa significación, las explicaciones espiritistas de los movimientos de las mesas tuvieron en principio una cierta latencia, pues quedaron solapados, como también hemos visto, por las interpretaciones fluidistas y magnetistas derivadas de la primacía que se dio a los giros sobre los golpes, es decir, a las rotaciones de las mesas sobre sus mensajes. En España, sólo a partir de 1854, cuando ya la fiebre de las mesas giratorias había sido olvidada por gran parte de la población, empezaron a mencionarse esporádica pero nítidamente en la prensa política y médica sus causas espiritistas. Ello posiblemente se debió a que, tanto en las sesiones familiares como en los experiencias de vocación más científica, aun cuando mucho menores ambas en número que las llevadas a cabo el año anterior, las respuestas de las mesas y sus capacidades parlantes adquirieron preponderancia sobre las rotaciones, es decir, que sus golpes pasaron a preocupar más que sus giros. Las dudas sobre si las mesas mediúmnicas obedecían no sólo a estos fluidos sino también a otras fuerzas «dependientes de un centro extraño, incomprensible e inteligente, desde el momento en que no se sujetan a ley física o química, calculada y lógica» ${ }^{86}$ se hizo cada vez más acuciante en esos todavía escasos círculos espiritistas embrionarios.

A partir de entonces el espiritismo fue aumentando su espectro fenoménico (se inventaron los psicógrafos y las planchettes, aparecieron espíritus, hablaron por boca de los médiums, volaron objetos...) y, aunque con no pocos meandros, fue cobrando carta de naturaleza, tanto aquí como en el resto del continente europeo ${ }^{87}$. En 1855 se fundó la Sociedad Espiritista de Cádiz, disuelta por la autoridad eclesiástica en 1857. Editado por esta sociedad, se publicó, todavía en ese año de 1857, el que pasa por ser el primer libro espiritista de nuestro país: Luz y verdad del espiritualismo. Opúsculo sobre la exposición verdadera del fenómeno, causas que lo producen, presencia de espiritus y su misión, cuya tirada acabó en la hoguera en un auto de fe.

La segunda sociedad espiritista se formó en Sevilla en 1861 y, un poco más tarde, se estableció en la capital la Sociedad Espiritista Española. Pero estas fundaciones no impidieron otro auto de fe en 1867, esta vez con la Noción del espiritismo, del médico Joaquín Huebles Temprado. Con la Revolución de 1868, conocida también como «La Gloriosa» o «La Septembrina», y la instauración del llamado Sexenio Democrático, el espiritismo se acabó desplegando

$86 \quad$ Ibídem, p. 43.

87 Para las etapas iniciales del espiritismo en España, véase:. MÉNDEZ BEJARANO, M. (s. a.), «El espiritismo», en: Historia de la filosofia en España hasta el siglo XX, Madrid, Renacimiento, 515-533; y Gullón, R. (1990), Direcciones del modernismo, Madrid, Alianza, pp. 135-136. 
por todo el territorio nacional, despliegue al que posiblemente contribuyeron los viajes y demostraciones de célebres médiums, como fue el caso del enigmático Daniel Dunglas Home (1833-1886), cuya presencia en España parece que tuvo lugar en esos años ${ }^{88}$. Pero esto es ya, seguramente, otra historia.

Fecha de recepción: 14 de julio de 2006

Fecha de aceptación: 5 de septiembre de 2006

88 MenÉndez Pelayo, M. (1992), «Artes mágicas y espiritismo», en Historia de los heterodoxos españoles [facsímil de la ed. de 1881], 3 vols., Madrid, C.S.I.C., II, 1400-1409; p. 1404. Sobre Home y sus sorprendentes facultades y demostraciones, véase: OPPENHEIM (1985), pp. 10-16. 